\title{
Examining the Nature of Learning within an Afterschool Mathematics Club: A Case Study of Four Learners
}

\author{
Penehafo Kaulinge - Pohamba ${ }^{1}$, Mellony H. Graven ${ }^{1}$ Debbie Stott $^{1} \&$ Daniel Opotamutale Ashipala ${ }^{2}$ \\ ${ }^{1}$ Education Department, Faculty of Education, Rhodes University, Grahams town, South Africa \\ ${ }^{2}$ Department of General Nursing Science, School of Nursing, University of Namibia, Keetmanshoop (UNAM), \\ Namibia \\ Correspondence: Penehafo Kaulinge - Pohamba, Namibian College of Open Learning (NAMCOL), P. O. Box 15008, \\ Windhoek, Yetu Yama Centre, Independence Avenue, Katutura, Namibia.
}

Received: October 21, 2016

Accepted: November 10, 2016

Online Published: November 22, 2016

doi:10.5430/irhe.v2n1p21

URL: http://dx.doi.org/10.5430/irhe.v2n1p21

\begin{abstract}
This study examined the nature of learning within an afterschool mathematics club established by the South African Numeracy Chair project. This study sought to establish what sort of progress in mathematical learning occurred in a grade 3 afterschool maths club, using assessment instruments associated with the Learning Framework in Number. The study also sought to understand the nature and effects of mentor mediation in the maths club, using Vygotsky's notion of the Zone of Proximal Development (ZPD) together with the notion and practice of scaffolding.

This study was interpretive in nature drawing on qualitative methods with some elements of quantification in relation to learners' progression. The club consists of 10 learners of mixed ability ( 5 girls and 5 boys) at a township school in Graham's town, South Africa. Learners in this case study were selected through purposive sampling. As part of the data collection strategies, the learners were interviewed twice in terms of their numeracy proficiency.

The assessment interview results revealed that, in terms of proficiency in early arithmetical learning, all four learners showed progress after spending four months in an afterschool maths club. This study also recommended Wright et al.'s (2006) LFIN framework to be used in assessing learners' progress in mathematics, as it could inform the refinement of instructional design within the school curriculum and teachers' education in the Namibian context.
\end{abstract}

Keywords: afterschool mathematics club, mathematic/numeracy proficiency, assessment intervention (LFIN) learning progression

\section{Introduction}

There is an on-going concern with the decline in mathematics achievement across grades level in South Africa. A number of studies have highlighted the fact that South Africa is facing what is termed a "maths crisis" (Fleisch, 2008). This is noted both locally and internationally. In tests on grade 8 pupils, South Africa came last in the 2003 Maths and Science indexes of the Trends in International Mathematics and Science study. South Africa also came last out of 40 countries in the 2006 Progress in International Reading Literacy Study. The poor grounding in numeracy and literacy in primary schools is regarded as a fundamental factor contributing to poor mathematical learning outcomes. Thus improving both the quality of the teaching and learning of mathematics and also the number of students with access to the foundation phase is among the top government initiatives aimed at addressing the numeracy challenge in the primary school.

Despite improved matric results after decisive steps were taken to improve quality, there is a body of evidence to show that the quality of mathematics ability in the majority of primary schools remains poor in South Africa. There is evidence that foundation skills of numeracy quality of learning outcomes, the mathematics performance of South African learners is amongst the lowest of middle income countries (that is, amongst those countries where such statistics are available).

Moreover, learner performance tests have also revealed that most South African primary scholars have a poor grasp of elementary foundational mathematical concepts, as reflected in the $30 \%$ average scores for both the 2001 grade 3 numeracy national tests and the 1999 Monitoring Learning Achievement (MLA-project Department of Education, 1999) grade 4 numeracy project, in which South Africa had the lowest score amongst the 12 African participating 
countries (OECD, 2008). In the three international and highly regarded TIMSS tests the local grades 7,8 and 9 maths scores were at the bottom of the maths league tables (Reddy, 2006; Howie, 2001). Scholars (2008) notes that the majority of South African learners do not have an understanding and knowledge of the basic number bonds (algorithms) and place value in the base-10 number system, and cannot readily understand the meaning of multiplication and division. Results from the TIMSS 2002 grade 8 tests also highlighted that the South African curriculum emphasises the application of mathematics to real-life situations and multicultural approaches at the expense of understanding and mastering basic fundamental mathematics concepts and skills (Reddy, 2006). Such criticism is warranted, given the fact that the official curriculum (Curriculum 2005) in early 2000 was characterised by under-specification of basic knowledge and skills (Reddy, 2006).

South African learners' performance in maths and numeracy in regional, sub-regional, national and international tests is indeed problematic and reveals the dismal maths situation South Africa currently faces.

More than half of South Africa's high school pupils were found to be functionally illiterate and innumerate, and the situation at primary school level was even more dire need, with only about $40 \%$ of grade 6 pupils meeting the standard for language achievement and $22 \%$ meeting the standard for maths. This incompetence was observed mostly in South African grade 8 learners' performance in mathematics and science in TIMSS in 1995. The study revealed that South African learners' did not have the required basic mathematical knowledge and their scores in mathematics and science were significantly lower than those of other learners in all the other participating countries in the second study (Meier, 2011).

\subsection{Problem Statement}

Studies pointed out that regardless of several efforts the South African government; learners continue to perform poorly in mathematics. Research and evaluations of mathematics education intervention point to the lack of foundational knowledge as one of the key factors for this poor performance. In addition, despite improved matric results after decisive steps were taken to improve quality of learners' performance in subject like mathematics, there is a body of evidence to show that the quality of mathematics ability in the majority of primary schools remains poor in South Africa. South African learners' performance in maths and numeracy in regional, sub-regional, national and international tests is indeed problematic and reveals the dismal maths situation South Africa currently faces.

The study focus is twofold: firstly the focus is on the development of mathematical proficiency in Grade 3 learners in after school maths clubs. This is done by exploring the nature of learning within a grade 3 mathematics club. Secondly the study focus on identifying mediation or scaffolding strategies that provides learning opportunities for learners participating in a math's club.

\subsection{Research Questions}

The following research question was posed: What is the nature of mentor to peer mediation in the afterschool maths club?

\subsection{Research Purpose}

The purpose of this study was to examine the nature of grade 3 learners' mathematical learning in an afterschool mathematics club.

\subsection{Research Objectives}

The objectives of this study were to:

- Explore the nature of learning within an afterschool mathematics club for learners in the primary grades in an after school mathematics club.

- Identify strategies that provide learning opportunities for students participating in a math's club.

\subsection{Significance of the Study}

This study aims to contribute to the growing area of research seeking solutions to the many numeracy education challenges faced in South Africa. The study aims to contribute to the literature about learning within afterschool mathematics programmes, particularly to help remedy the paucity of literature relating to young learner programmes. Additionally, while there is little research in this field in South Africa, there is none at all in Namibia. Thus the value of this study lies not only in researchers personal academic growth but, more importantly, in its capacity to provide insights into how to improve mathematics education in Namibia in the future. 
Furthermore, in the area of numeracy learning and afterschool mathematics clubs, especially in primary grades in South African and Namibian schools, little is known about the actual number knowledge of children and what strategies they use to solve number problems.

\section{Study Design and Methods}

This study was interpretive in nature drawing on qualitative methods with some elements of quantification in relation to learners' progression. As the name suggests, the interpretive paradigm is concerned with interpreting and understanding human actions. According to Merriam (2009, p. 213), the assumption underlying qualitative research is that reality is holistic, multidimensional and ever-changing; it is not a single, fixed, objective phenomenon waiting to be discovered and observed. The paradigm provides for multiple realities and the goal of my study was to understand a phenomenon that is not yet well understood. It assumes that the way to understand something is through studying it in its natural context (Cohen, Manion \& Morrison, 2011). In this case the nature of mathematical learning and proficiency progression for the selected grade 3 learners was investigated within the context of learners participating in an afterschool mathematics club.

\subsection{Population}

Participants targeted by this study consisted of 10 learners of mixed ability ( 5 girls and 5 boys) at a township school in Graham's town, South Africa.

\subsection{Sampling and Sample Size}

The sample size consisted of four grade 3 learners aged 9 to 11 was chosen for my study. The study was conducted with learners participating in an afterschool maths club in a township school situated in Graham's town, South Africa. Learners in this case study were selected through purposive sampling. Schumacher and McMillan (2001, p. 401) describe purposive sampling as a way of "selecting small samples of information-rich cases to study in-depth without desiring to generalize to all such cases". A balance of two boys and two girls were selected from the club of ten learners. The two boys and two girls were suggested by the mentors as learners who regularly and actively participated in club sessions and who displayed a range of numeracy proficiency. The four learners were purposefully sampled according to their general performance (abilities) in class and their ability to articulate ideas. According to Cohen, et al. (2011), using a purposive and convenient strategy is suitable for small scale research because it is less complicated to set up and there is no attempt to generalize one's findings.

\subsection{Data Collection Procedure (Instruments and Methods)}

As part of the data collection strategies, the learners were interviewed twice in terms of their numeracy proficiency (LFIN stages and levels) during the research, adapted from Wright, et al., (2006). The first was when the club first started while the second one was done after four months of club participation. This was done in order to collect the data for my research question one. Additionally, the four learners were regularly observed in club sessions and I used field notes, video and audio recordings throughout the observation period.

Finally, these learners were also interviewed in pairs using the task-based interviews in order to analyse how mediation of learning occurred. The use of multiple data sources was employed for the purpose of enhancing both validity and reliability and ensuring credibility through enabling triangulation (Cohen, et al., 2011). According to Merriam (2009), a key strength of the case study method involves using multiple sources and techniques in the data gathering process, i.e. observation, and individual task-based interviews with learners.

\subsection{Data Analysis}

Data analysis for this study was done in two parts: Firstly, transcriptions which consisted of descriptions of learners' levels and stages obtained and, where necessary, words and actions was used during the interview. Based on the transcriptions, a description of each child's levels and strategies for each aspect was written and general insights concerning their strategies were noted. In describing strategies, notes were made about distinctive features of each child's strategies. This quantification enabled the assessment and documentation of learners' number knowledge and the extent to which the progression occurred across the 9 aspects of early number knowledge in mathematics.

Secondly, qualitative data obtained through observations of the learners' extracts from field notes and reflective journal writing. I gathered two sets of data to address my two major questions. Data collected from video recordings of the four learners from the task based interviews were transcribed and analysed using the ZPD as an analytic tool. 


\subsection{Ethical Consideration}

Before commencing the research study; the research proposal was submitted to the South African Numeracy Chair at Rhodes University. The researcher had also applied for ethical clearance from both the Eastern Cape Department of Education (for broader club research) and through proposal, application was also submitted for ethical clearance through Rhodes University (for the specific study). Permission was also sought from the principal, teachers and parents of the participants.

\section{Results, Analysis \& Discussion: Mathematical Progression}

One of the major instruments used in the study is interview. The interview items, the Wright, et al. (2006) framework was adapted and used. The framework consisted of eight categories, each with its own levels or stages. However, scores were used for some aspects such as combining, partitioning and subtilizing in the absence of levels in the framework. Levels and stages were described earlier in the literature review.

\subsection{Numeral Identification (NI)}

Numerals are the written and read symbols for numbers. Learning to identify, recognise and write numerals is an important part of early arithmetical development (Wright, et al., 2006). Learners' knowledge of numeral identification was assessed by displaying numeral cards individually, and asking the learners' to name the numeral given number or whether the learner counted from 1 to respond to these tasks.

Table 1. Learners' levels in numeral identification (Note 1)

\begin{tabular}{lll}
\hline \multicolumn{3}{l}{ Numeral identification } \\
\hline & April & August \\
\hline Kaino & 4 & 5 \\
\hline Alleta & 3 & 4 \\
\hline Olien & 4 & 5 \\
\hline Elia & 3 & 4 \\
\hline
\end{tabular}

As shown in Table 1, none of the learners were below level 3 in this aspect at any point. In April, Alleta and Elia were at level 3, which means in April they were only able to identify numbers up to three digits long. However, in August they were both able to identify up to four-digit numerals within the range of 1000 and beyond. This implies that both Elia and Alleta, improved by moving from level 3 to level 4 .

According to the LFIN, for a learner to be at level three she/he could only identify numerals in the range 1-100. During the April assessment interview, when Alleta and Elia were asked to say the number 1025, they experienced problems expressing it correctly. However, the other two learners, Olien and Kaino, were able to identify up to 4-digit numbers and thus were placed at level 4. In August Alleta and Elia both managed to advance from level 3 to level 4 by identifying numerals including 4-digit numerals while Kaino and Olien who were already at level 4, moved to level 5.

There are various possible explanations for these results. First, the initial interview was conducted in March, just two months after the school year started and a week or two after the club started. The second interview was conducted in August; 4 to 5 months after the school year had commenced and the learners had been in the club for at least 4 to 5 months. The afterschool maths club included teaching recognition and writing of the numerals from 1-100 and beyond and the use of flash cards. Hence, the improvement might be as a consequence of the work that they did in the club such as identification of numbers using flash cards. Within the club, learners were also provided with extra books that they worked through solving different mathematical problems and one of the first books focused on numbers. However, the fact that the learners had attended four to five months of the club by the time of the second interview seems likely to be a contributing factor to the learners' mathematical proficiency progression.

3.2 Forward (FNWS) and Backward Number Word Sequence (BNWS), and Number Word after (NWA) and before $(N W B)$

BNWS and FNWS refers to the learners' ability to count a forward or backward sequence of number words as well as being able to identify numerals (Wright, et al., 2006). The creation of the number word sequence requires more than generating a rote count. To assess learners' BNWS or FNWS, learners were presented with a starting number and 
asked to start counting forward or backward (e.g. 1 to 32 or count backward from 10). The learner could also be asked to identify which number comes before or after a given number. Table 2 below shows the results of learners' levels in FNWS/NWA and BNWS/NWB.

Table 2. Learners' scores and levels in FNWS/ after and BNWS/before (Note 2)

\begin{tabular}{lllll}
\hline & $\begin{array}{l}\text { Forward Number } \\
\text { Words Sequence } \\
\text { (FNWS) }\end{array}$ & $\begin{array}{l}\text { Backward Number } \\
\text { Word Sequence } \\
\text { (BNWS) }\end{array}$ \\
\hline & $\begin{array}{l}\text { April } \\
\text { Level }\end{array}$ & $\begin{array}{l}\text { August } \\
\text { Level }\end{array}$ & $\begin{array}{l}\text { April } \\
\text { Level }\end{array}$ & $\begin{array}{l}\text { August } \\
\text { Level }\end{array}$ \\
\hline Kaino & 5 & 5 & 5 & 5 \\
\hline Alleta & 4 & 4 & 5 & 5 \\
\hline Olien & 5 & 5 & 5 & 5 \\
\hline Elia & 4 & 5 & 4 & 5 \\
\hline
\end{tabular}

In terms of FNWS and number words after, the table shows that none of the four learners was at a level lower than 4 in April and August. In April, Kaino and Olien were at the highest level on FNWS. They were both able to answer all the tasks on FNWS correctly within the range of 100 and beyond without dropping back. According to Wright, et al. (2006), for a learner to be judged to be at level 5 , he/she may need to be able to say forward number word sequences correctly without missing any number in the range of one to 100. This also applies to the backward number words sequence.

Elia and Alleta were only able to produce forward number word sequence in the range of 1 to 100 without falling back. Thus, in April their level in FNWS was 4. They both omitted some numbers in the counting number sequence and they were slow at counting. They found it difficult to produce sequences when they were required to go from one-digit numbers to two/three-digit numbers. For example, when Elia was asked to count-on from 48 to 68 , as it was recorded.

Overall, two learners, Kaino and Olien, were already at the highest level in April. That indicated they were facile with numbers in the range of 1 to 100 and beyond. The other two learners, Alleta and Elia, were at level 3. That indicated they were only facile in the range 1-30. In August, Alleta remained at stage 4 while Kaino and Olien remained at the highest level 5 joined by Elia who moved from level 4 to level 5 .

Overall when the first interview was conducted in April, there were already three learners, Kaino, Alleta and Olien, who were at level 5 in BNWS. This implied that the three learners were already fluent in this aspect of BNWS up to 100 and beyond. Elia was the only one who was at level 4, because he was only fluent with numbers up to 100 but not beyond. On the other hand, by August, all four learners in the study were fluent with numbers in the range of 1 to 100 and beyond, including Elia.

The reason for improvement in both FNWS and BNWS for Elia may be attributable to various factors. Both the afterschool maths club and the CAPS (2011) for grade 3 mathematics included the standard study of basic numbers up to 9, counting groups of up to nine objects, as well as saying FNWSs up to 100 and beyond. Clearly, these teaching topics considered together go a long way toward children attaining the goal of being facile with the FNWS in the range 1-100 and beyond.

The fact that the learners did a mental session in every club session could also have been a contributing factor to the learners' improvement in these aspects. Wright (2009) argues that children's apparent lack of progress in some aspects of LFIN such as BNWSs during the first years of schooling could be explained in terms of classroom practices. Secondly, according to the CAPS document, learners in grade 3 are supposed to know how to count forwards and backwards in $2 \mathrm{~s}, 5 \mathrm{~s}$ and $10 \mathrm{~s}$ between 0 and 500 . They are also expected to learn how to count forwards and backwards in $20 \mathrm{~s}, 25 \mathrm{~s}, 50 \mathrm{~s}$ and $100 \mathrm{~s}$ between 0 and 1000 . In August, these learners had progressed quite far in grade 3, which means that they might have been able to learn how to count backwards or forward in these number ranges in class.

\subsection{Strategies of Early Arithmetical Learning (SEAL)}

For example, a learner is given a collection of counters, e.g. 8, 15, or 27, and asked to count how many in all. The mentor (interviewer) takes note of how the learner counts, whether the learner knows the number words him/herself 
and whether the learner correctly coordinates the number words with the items. The way the learner responds to the question, gives an indication of his or her current counting procedures.

Table 3. Learners' results in terms of stages of early arithmetical learning

\begin{tabular}{lll}
\hline & \multicolumn{2}{l}{$\begin{array}{l}\text { Strategies of Early Arithmetical } \\
\text { Learning }\end{array}$} \\
\hline & April & August \\
\hline & Stage & Stage \\
\hline Kaino & 3 & 4 \\
\hline Alleta & 2 & 3 \\
\hline Olien & 2 & 4 \\
\hline Elia & 2 & 3 \\
\hline
\end{tabular}

Table 3. (Note 3) learners' stages of the SEAL

The table shows that none of the four learners was found to be in the emergent stage (stage 1), during the first interview in April. Thus, most learners were able to answer the questions in April (although not quickly) and they depended on counting from one, rather than counting on, and did not make use of mathematical strategies. Hence, three of them were at stage 2, except Kaino, who was the only learner already at the advanced counting stage 3 . The other three learners, Elia, Olien and Alleta, were at the figurative stage (stage 2) of early arithmetical learning.

As reflected in her interview, Kaino was rated at stage three in April because of her ability to use 'counting on' strategies in solving problems such as $16+9$ rather than 'counting from' strategies. Although she used her fingers to symbolize number 9, it seemed she was able to count on, rather than counting from. Wright, et al. (2006) call this anticipation and capacity to keep track of the number of counts the hallmark of stage 3 .

In comparison, the August results show that all four learners progressed up at least one stage. Olien progressed to stage 4 while Alleta and Elia moved to stage 3. Elia was able to use the counting on and backwards strategies. For example, when he was asked to count $12-5$; he was able to count backwards but he was still counting in 'ones'. According to Wright, et al. (2006), a learner at stage 3 must be able to use a counting-on rather than a counting-from strategy.

At one point Alleta was asked to add 10 to 294 (in task 10, adding/subtracting with tens). Although she struggled a bit, she managed to get the answers by using her fingers to count forward from 294 and she finally got to the correct answer. In the same task, she was similarly observed using a count-down strategy. This showed that she was at a different stage compared to the strategies she used in April. This stage of performance according to Wright, et al. (2006) was stage 4. A learner who is at stage 4 will be able to use a countdown-to strategy to solve missing subtrahend tasks. In another example, in task 10a) add 10 to 92 , Kaino counted on from 92 and in the process, reverted to using her fingers while counting on to 102 .

Moreover, as the Table 4 reflects the early arithmetical learning stage model, during the April interview, the results show that three of the learners were at stage 2 (figurative counting) while only Kaino was at stage 3 (the initial number sequence). By August, of the 3 learners who were at stage 2, only Elia had advanced to stage 3. Alleta and Olien advanced two stages to stage 4 . Kaino advanced to stage 4 from stage 3. Interestingly, 2 of the 4 learners advanced more than one stage by August, showing that 3 of the 4 learners (Kaino, Olien and Alleta) were at stage 4, the highest level in the SEAL model. In other words, all four learners were able to make progress in their strategies of early arithmetical learning stages between April and August.

One of the noted errors was in part two of the assessment interview, question 12, 43-15= on this question 2 out of 4 learners switched the order of the unit subtraction in order to subtract. Some learners were observed subtracting 10 from 40 and then 5 from 3 (as shown in the example below). 
The subtraction of a larger unit digit from a smaller unit digit is noted by many researchers as one of the errors frequently made by children (e.g. Young \& O'Shea, 1981; Brown \&Van Lehn, 1982; Ashlock, 1982, as quoted in Wright \& Rumiat, 2010). The teaching of the standard written algorithm was identified as a factor which contributes to this error. This has led to the suggestion that is would be better to defer the teaching of standard written algorithms until the later years of schooling, and to wait until children have a strong conceptual understanding of tens and ones. In the early years, it is better to support children to invent their own algorithms (Kamii, 1998, cited in Wright \& Rumiat, 2010).

From Table 3, we see that when the August interview was conducted, learners were in a better position to display their knowledge of counting strategies and had made progress. This might be as a result of time spent on this strategy in class. From personal observation, in almost every club session, the mentor made sure that she emphasized quick and efficient mental strategies for calculations with number. In an informal conversation with one of the mentors she said she did not necessarily follow the curriculum but rather focused on building on where the learners were in terms of their mathematical knowledge. Additionally, from that same conversation, it was noted that developing more efficient strategies was among the top priority topics learned in the club.

\subsection{Base-ten Arithmetical Strategies (BTS)}

Base-ten strategies refer to the learners' knowledge of tens and one structures of the numeration system (Wright, et al., 2002). To determine children's levels in base-ten arithmetical strategies, they were asked to solve different types of tasks such as add 10 to 92 or use ten-dot strips. The interviewer observed whether the child counted by tens or by ones.

Table 4. Learners' level of development of base-ten arithmetical strategies

\begin{tabular}{lll}
\hline & \multicolumn{2}{l}{ Arithmetical Strategies (BTS) } \\
\hline & April & August \\
\hline Kaino & Level & Level \\
\hline Alleta & 3 & 3 \\
\hline Olien & 2 & 3 \\
\hline Elia & 2 & 3 \\
\hline
\end{tabular}

Table 4. (Note 4) learners' levels of BTS

The results suggest that both Alleta and Kaino were already at facile level (level 3 or up) of base-ten in April and remained there in August. Here, they were able to see ten as a unit comprising ten and were also able to solve addition and subtraction tasks involving tens, without using materials. Unlike other aspects of this interview, base-ten is one of the aspects where most learners rarely depended on visual material to get the answers. In both April and August Elia was found to be at the foundation concept of ten level, in which he was only able to see ten as a unit composed of ten ones. Moreover, being at level two of the base-ten arithmetical strategies shows that Elia found it hard to successfully solve at least $90 \%$ of the addition and subtraction sentence tasks when those tasks were presented as written problems. As Table 4 shows, all four learners were able to see ten as a unit of ten ones. However, it was a challenge to assign levels to these learners as they relied on counting-on or counting back strategies to solve most of the addition and subtraction problems that involved tens and ones, more especially during the April interview.

Overall, there seems to have been no progression in terms of shift from one level to another (with the exception of Olien who progressed one level). However from an observational point of view there was a slight progression in terms of learners' strategies within the same levels. The shift in levels here refers to the learners' ability to improve the initial base-ten arithmetical strategies but the improvement does not make them to move to the next level. For example Kaino's base-ten strategies were at facile level (level 3) and again in the second round of the interview she was still at level 3. From the interview one could see that Kaino has improved in her strategies but based on the different criteria assigned she remained at level 3. Thus from looking at her work, one could see the shift within level 3 . This shift could have occurred because of the strategies Kaino used during April and most likely depended on the materials she used compared to the ones she used in August. It was not so clear why these grade 3 learners or former grade 2 learners faced 
difficulties in solving two digit addition and subtraction problems. As per the curriculum document, these competencies were intended to be mastered at grade 2 level.

\subsection{Combining and Partitioning}

Combining and partitioning refers to joining or separating collections. To assess learners' progression in these aspect learners were asked to give two numbers that add up to 10 (combining) or asked to partition the number seven. Wright, et al.'s (2006) LFIN makes no provision for levels for assessing learners' progression in terms of combining and partitioning. Hence, to determine learners' progression in this regard, I needed to make use of percentage scores of correctness.

Table 5. The average total scores of each of the four learners for partitioning and combining

\begin{tabular}{lll}
\hline & \multicolumn{2}{l}{ Combining and Partitioning } \\
\hline & April & August \\
\hline Kaino & $100 \%$ & $100 \%$ \\
\hline Alleta & $75 \%$ & $88 \%$ \\
\hline Olien & $100 \%$ & $100 \%$ \\
\hline Elia & $100 \%$ & $100 \%$ \\
\hline
\end{tabular}

Table 5. Learners' scores for combining and partitioning

The results suggested that in April, three learners (Kaino, Olien and Elia) were able to answer all the questions on combination and partitioning. They were able to find the complement of a number to make 5 or 10 quickly and were able to give at least two partitions of a number, as this was the kind of question asked in the interview. One learner Alleta scored $75 \%$ and this shows that she was only able to find the complement of a number to make 5 without counting by ones. She was only able to give one or two partitions of a number. Alleta showed improvement in finding the complement of the number to make 5 or 10 but she was not as quick as the other three learners. Alleta was the only learner not to achieve $100 \%$ in August.

\subsection{Spatial Patterns and Subitizing}

The spatial patterns and subitizing refers to the assessment of whether the learner is able to instantly recognise and allocate a number word to a small group of perceptual items. To assess learners' progression in spatial and subitizing, the interview gave a range of tasks. For example learners were shown a card showing bags of apples for about 10 seconds and the learner was asked to say how many apples there were altogether.

Table 6. Learners' scores in spatial patterns and subitizing

\begin{tabular}{lll}
\hline \multicolumn{3}{c}{ Subitizing } \\
\hline & April & August \\
\hline Kaino & $100 \%$ & $100 \%$ \\
\hline Alleta & $93 \%$ & $93 \%$ \\
\hline Olien & $100 \%$ & $100 \%$ \\
\hline Elia & $93 \%$ & $100 \%$ \\
\hline
\end{tabular}

Table 6. learners' total average scores in subitizing

There was no model in LFIN for determining learners' levels in subitizing and spatial patterns. Hence, to determine learners' progression, I made use of percentage scores. As shown in Table 6, the highest score was $100 \%$ and the lowest was 93\%. Kaino and Olien scored 100\% while Alleta and Elia had scores of 93\% in April. 
In comparing learners' August results with the April scores, the table shows that while there were only two learners with 100\% scores in April, during August only Alleta did not score 100\%. In summary, the table shows progress in terms of Elia's performance with a 7\% increase in August, while the other three learners retained their April scores. Overall, subitizing was an aspect where learners performed well. Wright, et al. (2006) argue that activities that involve subitizing have an important role in young children's numerical development.

\subsection{Early Multiplication and Division}

Students' early knowledge of multiplication and division is based on the development of counting sequences, the skills of combining, partitioning and patterning and the students' ability to use equal groups.

Table 7. Learners' levels in early multiplication and division

\begin{tabular}{lll}
\hline & \multicolumn{2}{l}{ Multiplication and Division } \\
\hline & April & August \\
\hline Kaino & 2 & Level \\
\hline Alleta & 2 & 3 \\
\hline Olien & 2 & 2 \\
\hline Elia & 1 & 2 \\
\hline
\end{tabular}

It should be noted that multiplication and division topics per se were not tackled directly in the clubs although some repeated addition and sharing 'word' problems were regularly included. Thus perhaps learners drew on their prior-knowledge from previous grades, or from their work in the grade 3 classroom or their everyday knowledge to answer some of the questions in this section e.g. show the 10x2 array of dots. Table 7 shows that in April at least three learners out of four were at stage 2, except Elia who was still at the initial grouping and sharing stage.

Table 8. Summary of learners' progression across all LFIN aspects

\begin{tabular}{|c|c|c|c|c|c|c|c|c|c|c|}
\hline \multirow[b]{2}{*}{ Learners } & \multicolumn{5}{|c|}{ APRIL } & \multicolumn{5}{|c|}{ AUGUST } \\
\hline & $\boldsymbol{K}$ & $\boldsymbol{A}$ & $\boldsymbol{O}$ & $\boldsymbol{E}$ & & $\boldsymbol{K}$ & $\boldsymbol{A}$ & $\boldsymbol{O}$ & $\boldsymbol{E}$ & \\
\hline $\begin{array}{l}\text { Aspect } \\
\text { (highest aspect level / stage) }\end{array}$ & & & & $\begin{array}{l}\text { No learners at } \\
\text { highest level }\end{array}$ & & & & & & $\begin{array}{l}\text { No learners at } \\
\text { highest level }\end{array}$ \\
\hline NI (4) & 4 & 3 & 4 & 3 & 2 & 4 & 4 & 4 & 4 & 4 \\
\hline FNWS (5) & 5 & 4 & 5 & 4 & 2 & 5 & 4 & 5 & 5 & 3 \\
\hline BNWS (5) & 5 & 5 & 5 & 4 & 3 & 5 & 5 & 5 & 5 & 4 \\
\hline SEAL (5) & 3 & 2 & 2 & 2 & 0 & 4 & 4 & 4 & 3 & 0 \\
\hline BTS (3) & 3 & 3 & 2 & 2 & 2 & 3 & 2 & 2 & 2 & 1 \\
\hline EARLY MULTI/ DIVISION (3) & 2 & 2 & 2 & 1 & 0 & 3 & 2 & 2 & 2 & 1 \\
\hline $\begin{array}{l}\text { Aspect } \\
\text { (highest scores) }\end{array}$ & & & & & $\begin{array}{l}\text { No l's } \\
\text { with } \\
\text { highest } \\
\text { scores } \\
\end{array}$ & & & & & $\begin{array}{l}\text { No l's with highest } \\
\text { scores }\end{array}$ \\
\hline $\begin{array}{l}\text { COMBINING \& PARTIONING } \\
(100 \%)\end{array}$ & 100 & 75 & 100 & 100 & 3 & 100 & 88 & 100 & 100 & 3 \\
\hline SUBSITISING (100\%) & 100 & 93 & 100 & 93 & 2 & 100 & 93 & 100 & 100 & 3 \\
\hline
\end{tabular}

However, when the interviews were conducted for the second time in August, Kaino and Elia had advanced by one level while Alleta and Olien made no progress. Kaino moved from level 2 to level 3 and Elia moved from level 1 to 2. 
Two possible explanations for this are that on both occasions when the interview was conducted, the club had not covered the topic of division and multiplication in detail, if at all. In a personal conversation with one of the club mentors, she indicated that it was not easy for them to cover those two topics, because, from their observations, learners still needed to consolidate the operations of addition and subtraction. There was also much ground to be covered as some learners seemed to be a grade level behind in some cases, so the club focused on some of the basic topics such as numeral identification before they moved to other topics including multiplication and division.

\section{Summary of Learners' Mathematical Proficiency Progression Based on the Interview}

In terms of the interview-based assessment a summary of learners' progression is presented in Table 8 which shows learners' overall levels; scores and/stages in the different aspects of the LFIN for April and August. Table 8 indicates learner progression across all the LFIN aspects. We can see that there is general improvement across all LFIN aspects. For example in FNWS and BNWS, the number of learners at the highest level increased by 1 from April to August. Numeral Identification shows a pleasing growth from 2 learners at highest level in April to a full complement of 4 in August. The Strategies for Early Arithmetical Learning aspect shows the greatest progress where 2 learners progressed at least one level while two learners improved by two levels. However, none of them achieved the highest level of 5.

Although there is not a great deal of change shown in combining and partitioning, what can be seen is that Alleta increased her score by a substantial 13\%. In subsidising, 3 learners achieved 100\% and Elia increased his score by $7 \%$.

What is interesting is that this progress across all LFIN aspects was made over the period from mid-April to mid-August, a period of just over 2 school months. Possible explanations for this progress could be the focus in the club sessions on activities to develop efficient mental strategies, use of flash cards for place value work and for number recognition work.

\section{Discussion}

From the excerpts discussed above, it was evident that both mentors' ways of scaffolding followed similar patterns. Both started with setting the scene before moving on to give the learners the opportunity to explore their own strategies and reflect on their own work before the mentor got involved and adjusted the scaffolding practices based on the way the learners worked on the task. Additionally, both mentors in these excerpts demonstrated similar scaffolding practices, more especially the way they handled the learners when learners seemed to be experiencing difficulty or where they seemed to hit a ceiling. For example, this was evident in excerpt 2 for the girls (turn 35-49), and in excerpt 2 for the boys (turn 49 to 59). In both cases, each mentor provided more directed scaffolding through modelling and guiding (primarily through directing, prompting, and funnelling) when learners indicated or it was apparent that they were not progressing. In the case of the girls this was when they expressed that they 'did not know' (line 35) while for the boys this occurred after several attempts to find three numbers indicated a persistent guess and check strategy which was not leading to success.

The on-going scaffolding and increased direction at these points seemed to keep all four of the learners focused on the mutual goals of the activity. As it can be seen with the girls, in excerpt 1, the learners found it hard to find a value for the triangle. But, immediately after the mentor adjusted the scaffolding style, Alleta managed to come up with a strategy that helped her to get the answer in excerpt 3. In another example with the boys Elia had also a problem finding the next set of three numbers which add up to 38 but soon after the mentor suggested the new strategy through directed modelling he got a correct set of three numbers and screamed 'I know it, I know it, this one, this one, this one' (turn 58).

In each of the excerpts however there were few learner to learner 'catching each other's' thoughts except when explicitly prompted to reflect and share by the mentor. Additionally in these excerpts learners appeared to be progressing through the ZPD at different paces and in different ways. 'Aha' moments happen at different points for different learners and they did not happen simultaneously even when the mentor addressed both learners. It appeared that mentor scaffolding of learners who had not yet suggested an answer often involved reflection in terms of sharing whether they agreed with the other learner's suggestion or the other learner's work. In this respect the nature of the scaffolding practices was different for the learner who suggested a strategy or answer first and the learner who was required to assess or agree with the learner who suggested and provided the answer first.

\section{Conclusions}

This study revealed various degrees of progress in mathematical learning. In terms of their progress in the different aspects of number knowledge, the findings indicated that the four learners progressed diversely in a range and combination of aspects after spending four months in the afterschool maths club. The findings indicated that among the four learners, progress in terms of early number knowledge was more clearly visible in learners who showed weak number knowledge at the beginning. The findings of this study could therefore be used to address the current profound 
and persistent inequalities within society, the poor quality of teaching and learning mathematics, and the poor mathematical performance of the majority of South Africans and Namibians.

Therefore, these study findings could be used to contribute to the growing area of research seeking solutions to the many numeracy education challenges faced in South Africa. Additionally, while there is little research in this field in South Africa, there is none at all in Namibia. Thus the value of these study findings lies in its capacity to provide insights into how to improve mathematics education in Namibia and in the future.

The results of this study had revealed implications for an afterschool education policy both in Namibia and South Africa. It can be concluded from the findings of this study that in the foundation phase, learners stay at school until $14 \mathrm{~h} 00$, and thereafter either go home or play in the playground. This time could possibly be used more effectively for extended mathematics instruction.

\section{Limitations of the Study}

There are several limitations to this study, including the fact that the findings for this case study are not generalizable due to the small number of participants involved. The findings could thus be developed through further research that focuses on a broader sample of participants.

\section{Recommendations}

The following recommendations can be made based on the findings of this study:

This study suggests that Wright et al.'s (2006) LFIN framework is a useful way of assessing learners' progress in mathematics, and one that could inform our refinement of instructional design within the school curriculum and teachers' education in the Namibian context. My intention is to use this framework to support teachers in conducting interviews with learners in order to make full use of the framework and its potential.

\section{Acknowledgements}

We thank all the respondents who took time to take part in the interviews for this study, without their participation this study would not have been even a success or even possible. We also thank the Department of education for having granted us the permission to conduct research on its Schools.

\section{Competing interests}

The authors declare that they have no financial or personal relationship(s) which may have inappropriately influenced them in writing this article.

\section{References}

Cohen, L., Manion, L., \& Morrison, K. (2011). Research methods in education (7th ed.). New York: Routledge.

Department of Basic Education. (2011). Curriculum and Assessment Policy Statement Grades 1-3 Mathematics. Pretoria: DBE.

Department of Basic Education. (2011b). Report on the Annual National Assessments of 2011. Pretoria: DBE.

Department of Education. (2010). Curriculum and Assessment Policy Statement (CAPS), Mathematics-Foundation Phase: Final draft. Pretoria: DoE.

Fleisch, B. (2008). Primary education in crisis: Why South African schoolchildren underachieve in reading and mathematics. Johannesburg: Juta.

Howie, S. (2001). Mathematics and science performance in Grade 8 in South Africa. 1998/1999. Pretoria: Human Sciences Research Council.

Meier, C. (2011). The Foundations for Learning Campaign : helping hand or hurdle ? South African Journal of Education, 28(1) 549-560. South Africa: EASA. Retrieved 20 September 2012 from http://www.sajournalofeducation.co.za/index

Merriam, S. B. (2009). Qualitative research and case study: Applications in education (2 ${ }^{\text {nd }}$ ed.). San Francisco: Jossey-Bass.

Organisation for Economic Development (OECD). (2008). Review of National Policies for Education. South Africa, Pretoria.

Reddy, V. (2006). Mathematics and science achievement at South African schools in TIMSS 2003. Cape Town: Human Sciences Research Council. 
Schollar, E. (2008). Final Report: The Primary Mathematics Research Project 2004-2007. Towards evidence-based educational development in South Africa. Johannesburg. Retrieved 20 September 2012 from www.jet.org.za/events/conferences/.../Papers/...pdf/at_download

Schumacher, S., \& McMillan, J. (2001). Research in education ( $3^{\text {rd }}$ ed.). New York: Harper.

Wright, R., \& Rumiat, R. (2010).Assessing the number knowledge of children in the First and Second Grade of an Indonesian School. In L. Sparrow, B. Kissane \& C. Hurst (Eds.), Shaping the future of mathematics education. Proceedings of the 33rd annual conference of the Mathematics Education Research Group of Australasia. Fremantle: MERGA. Retrieved from https://books.google.com.na/books?isbin=9460919707

Wright, R.J. (2002). Assessing young children's arithmetical strategies and knowledge: Providing learning opportunities for teachers. Australian Journal of Early Childhood, 27(3), 31-36. Retrieved 20 September 2012 from https://books.google.com.na/books?isbn=1446253686

Wright, R.J., Martland, J., \& Stafford, A.K. (2006). Early numeracy: Assessment for teaching and intervention. London: Paul Chapman Publishing/Sage.

Wright, R.J., Martland, J., Stafford, A.K., \& Stanger, A.K. (2002). Teaching number: Advancing children skills and strategies (2nd ed.). London: Paul Chapman Publishing.

\section{Notes}

Note 1. Levels in numeral identification: 1 One digit numeral -Able to identify 1-digit numerals, 2 Two-digits numeral -Able to identify 2-digit numerals, 3 Three-digits numeral -Able to identify 3-digit numerals' 4 Four-digits numeral -Able to identify 4-digit numerals

Note 2. For NWA and NWB, the child's level is determined using the model shown in chapter 2 table 3 and table 4 for BNWS and NWB, Table 2.1: Model for Construction of Forward Number Word Sequences

$$
0 \text { emergent, }
$$

Note 3. Stages: 0 Emergent, 1 perceptual, 2 Figurative, 3, advanced-counting by ones and 4 Facile.

Note 4. Levels of BTS: 1 Initial concept of ten, 2 Intermediate concepts of ten and 3 facile concept of ten. 